\title{
El castillo y las fortificaciones de Calatayud: estado de la cuestión y secuencia constructiva
}

\author{
Herbert GonZÁLEZ ZyMLA \\ Dpto. de Historia del Arte I (Medieval) \\ Universidad Complutense de Madrid \\ hgonzale@pdi.ucm.es
}

Calatayud debe buena parte de su fortuna histórica, económica y artística a su posición estratégica, en el centro de la depresión formada por los ríos Jalón y Henares. El Jalón, afluente del Ebro, conforma un corredor natural que conduce directamente a Zaragoza y al Mediterráneo. El Henares, afluente del Tajo, forma un segundo corredor natural unido al anterior a través de varios cañones naturales, que conecta la depresión del Ebro con la Meseta Central a través de Medinaceli y Guadalajara. El Jiloca, uno de los afluentes del Jalón, forma un tercer valle fluvial que, en su cabecera, se conecta con el Turia y permite llegar hasta Valencia. Por último, bordeando las estribaciones del Moncayo, se llega, siguiendo el valle del Isuela y el Queiles a Tarazona, Tudela y las cadenas montañosas cantábrica y pirenaica. Calatayud es, por tanto, una posición geográfica en la que confluyen cuatro caminos naturales que unen el Mediterráneo con la Meseta y el Norte. La fundación de Augusta Bilbilis, a finales del siglo I a.C., heredera de una ciudad celtibérica preexistente, cuyas ruinas se encuentran en Huérmeda, demuestra que Roma fue consciente de que para controlar la Celtiberia era necesario hacerlo desde este punto geoestratégico ${ }^{1}$. Por otro lado, fundar Bilbilis, constituía un mensaje claro de permanencia y control del territorio a las poblaciones autóctonas.

En lo geofísico, Calatayud se encuentra en el centro de una hoya ovalada de 100 $\mathrm{km}$ de longitud y 20 de anchura máxima, rodeada por las sierras de Ateca, Vicor y la Virgen, compuestas todas ellas por materiales geológicos sedimentarios del terciario (margas grises, yesos y sales solubles) responsables de la formación de barrancos muy erosionados, con paredes verticales de más de $40 \mathrm{~m}$ de altura, que, al degradarse, forman cárcavas y páramos pelados de apariencia desértica. La vegetación y la tierra fértil se concentran en el centro de la hoya, en el entorno de los cursos de agua, que vistos desde posiciones dominantes resultan ser verdaderos oasis de verdor rodeados de páramos desérticos. Este paisaje debió ser muy valorado por los musulmanes cuando en el 714 tomaron Zaragoza. La historiografía tradicional acepta que Calatayud fue una de las fundaciones musulmanas más tempranas

1 M. MARTÍN BUENO (coord.), Cuaderno de campo. Grupo Urbs. Augusta Bilbilis, Labitolosa, Los Castellazos y Valdeherrera, Zaragoza, 2009. 
al atribuirla al III valí, Ayyub ibn Habib al Lajmi, que gobernó al-Andalus durante seis meses del $716^{2}$. Vicente de la Fuente afirma que debemos el conocimiento de esta fecha a Mohammad ben Zuleiman, autor de una Historia de Calatayud, escrita hacia 1120, inmediatamente después de la conquista cristiana, hoy perdida, pero citada por autores medievales y modernos ${ }^{3}$. Al ser una fuente secundaria y tardía, la data fundacional no resiste un juicio crítico severo. La historiografía actual está de acuerdo en que el nombre Calatayud es consecuencia de la contracción del topónimo Qal'at Ayyub, que significa el castillo de Ayyub, forma musulmana del nombre judío Job, acaso su primer alcaide ${ }^{4}$. Esta segunda hipótesis afirma que la ciudad no fue fundada por musulmanes, sino por judíos y que, rodeada de una muralla potente y fortificada con un castillo cuyo alcaide era Job, constituía un punto clave en el control de los valles. Aliados de los musulmanes, con el paso del tiempo, se produjo una sustitución de la elite de poder, primero, en el siglo VIII los judíos fueron desplazados por musulmanes leales a los Omeyas, y luego, en el siglo XII, los musulmanes fueron desplazados por cristianos ${ }^{5}$. La arqueología urbana no ha conseguido

2 Era primo hermano de Abd al-Aziz y sobrino de Musa ben Nusayr.

3 V. DE LA FUENTE, Historia de la siempre augusta y fidelísima ciudad de Calatayud, Calatayud, 1880, (edición facsímil, Zaragoza, 1982). Entre quienes se pronunciaron a favor de la identificación del fundador de Calatayud como el emir interino Ayyub están, la crónica de Ximénez de Rada, Jerónimo Zurita, Beuter, Blancas, el Padre Mariana, Seybold y Lévi Provençal. Entre quienes lo niegan se debe destacar a Masdeu y Codera, que afirma que en seis meses no tuvo tiempo suficiente para levantar un conjunto fortificado tan sobresaliente. Vicente de la Fuente dijo que este argumento no era suficiente para invalidar la fundación puesto que "amigos, partidarios o súbditos suyos puede que quisieran honrar con aquel nombre la naciente colonia"; J. ZURITA, Anales de la Corona de Aragón, Zaragoza, 1585; M. COS y F. EYRALAR, Glorias de Calatayud y su antiguo partido, Calatayud, 1845; J. M. PÉREZ DE NUEROS, Historia, antigüedad y grandeza de la muy noble, augusta ciudad municipal de Bílbilis en lo antiguo y en lo moderno, la fiel ciudad de Calatayud. B.N.E, ms. I-214; A. G. CHEJNE, Historia de la España Musulmana, Madrid, 1980, p. 21. "Toma este Arcedianado su apellido de Calatayud, ciudad ilustre y poblada en el mesmo tiempo que los moros se apoderaron de España: y su poblador fue el rey Ajub Abovalid, el que volvió la silla Real de los Árabes a Córdoba: su fundación fue en el año setecientos y diez y nueve; y como obra y como hechura real, se le dio y puso el mismo nombre del rey su fundador." M. MARTÍNEZ DEL VILLAR, Tratado del Patronato, Antigüedades, Gobierno y Varones Ilustres de la Ciudad de Calatayud y su Arcedinado, Zaragoza, 1598, II parte, I, p. 44.

4 Conviene recordar la importante presencia judía en Calatayud desde la época musulmana hasta 1492. A. LÓPEZ ASENSIO, La judería de Calatayud. Sus casas, calles y barrios, Zaragoza, 2003. Cenac de Moncau afirma que "Calatayud sería una puebla hebrea qal at al Yaud": C. DE MONCAU, Histoire des peuples et des etats pyreneens. Amyot, 1860.

5 No es este, ni mucho menos, el único caso documentado en España de castillo de judios, fortificado, más o menos independiente y situado en un área clave para el control del territorio. Deben citarse el interés comparativo del castro de los judíos en León y el castillo judío de Molina de Aragón. El castro iudeorum de León existía ya a mediados del siglo X y fue arrasado en 1196 por los cristianos, quedando totalmente despoblado. J. RODRÍGUEZ FERNÁNDEZ, La judería de la ciudad de León, León, 1964; R. MARTÍNEZ PEÑÍN, "La judería altomedieval de la ciudad de León: fuentes documentales y datos arqueológicos.", Miscelanea Medieval Murciana, XXXI (2007), pp. 123-138. La judería de Molina fue dominada por los cristianos desde el siglo XI y despoblada tras el decreto de 1492. A. HERRERA CASADO, Veinte siglos de historia. Un manual básico para conocerla, Guadalajara, 2000; Ibídem, Castillos de Guadalajara, Guadalajara, 2000, pp. 156-163; J. A. ARENAS ESTEBAN, J. P. MARTÍNEZ NARANJO, y T. DAZA BLAZQUEZ, "El 'Prao de los judíos' de Molina de Aragón: resultados de siete años de trabajo", I Jornadas de Arqueología de Castilla la Mancha, Cuenca, 2007, pp. 705-732. En el caso de Calatayud, a mediados del siglo VIII debió ser sustituida la elite de gobierno judía por aristócratas musulmanes leales a los Omeyas. Desde el siglo XII la elite musulmana fue desplazada por la cristiana y, una parte de la judería, acabó controlada por el monasterio de Piedra, que era propietario de la Alcaicería bilbilitana, de modo que cualquier negocio que se 
aclarar si Calatayud existía ya en la segunda mitad del siglo VIII, pero ha arrojado mucha luz acerca de los periodos anteriores y posteriores.

Tal y como llega a nuestros días, el recinto fortificado de Calatayud está formado por 6 castillos diferentes, llamados actualmente: 1: castillo de la Consolación, Torre Mocha o Cocción de los moros; 2: castillo de Ayyub, Mayor o Plaza de Armas; 3: castillo Real, del Reloj, lo Pidado o lo Picado; 4: castillo de Doña Martina o de Don Álvaro; 5: castillo de la Peña. Por último estaría el castillo del Masilón, en el término de Barbusier. Uniéndolos se construyeron una serie de murallas formando un recinto de planta irregular que se adapta a la topografía. Si los estudiamos siguiendo un orden cronológico, la secuencia constructiva sería la siguiente.

El castillo de Doña Martina, llamado también castillo de Don Álvaro, por haber sido su alcaide en el siglo XIV el padre de Don Álvaro de Luna ${ }^{6}$, está limitado al norte por el barranco de Soria, al oeste por el barranco de las Pozas, al este por el barranco de la Rúa y al sur por la cuesta de Santa Ana. En él se han localizado fragmentos cerámicos de la Edad del Bronce (s. XIII a C.), celtíberos (s. VI a.C.) ${ }^{7}$, romanos clásicos (s. I d. C.), tardoantiguos (s. VI d.C.) y de la etapa del emirato dependiente (714-756), algunos de los cuales se conservan en el Museo Arqueológico de Calatayud y otros en Zaragoza ${ }^{8}$. Este asentamiento está condicionado por la necesidad de aprovechar las paredes rocosas de yeso de la montaña como defensa natural. Actualmente se sitúa en el centro de Calatayud y es el edificio militar que tiene mayor superficie de todos los que conforman su recinto fortificado. En realidad, más que una plataforma geológica o cerro testigo, era una prolongación de la meseta sobre la que se asienta el castillo de la Torre Mocha, segregada de aquella al excavarse el foso barranco de las Pozas. Zozaya defendía que, pese a tener varias fases constructivas difíciles de distinguir, este castillo era en sus zócalos del sector norte, obra del siglo VIII, construida con sillares de piedra caliza, de tendencia isódoma, escuadrados y colocados a soga, acaso reutilizados de las ruinas de Bilbilis y engatillados unos con otros en una técnica que está presente también en Santa María de Melque. Su planta es aproximadamente rectangular, de $140 \mathrm{~m}$ de largo. En el sector norte se conservan otros paramentos murales que marcan una segunda fase constructiva, labrados en sillarejo dispuesto en hiladas más o menos regulares en cuyo extremo oriental emplazaron un torreón con un arco apuntado de ladrillo. En el paramento mural occidental, necesitado de contrafuertes para preservar la estabilidad del muro, se documenta un muro construido en sillarejo mampuesto reforzado

abriese rentaba alquileres favorables a la abadía cisterciense. H. GONZÁLEZ ZYMLA, Historia y arte en el Real Monasterio Cisterciense de Santa María de Piedra, tesis doctoral manuscrita, Universidad Complutense de Madrid, 2011, tomo I, pp. 700 y ss.; Ibídem, "Fuentes materiales y documentales para el estudio de las relaciones del monasterio cisterciense de Santa María de Piedra con las juderías del entorno", Congreso de Arqueología Judía Medieval en la Península Ibérica. Balance y perspectivas, (en prensa).

6 J. B. LABAÑA, Itinerario del reino de Aragón, Zaragoza, 1895.

7 De hecho, en la cúspide del cerro del castillo de Doña Martina se emplaza el yacimiento arqueológico de Bilbilis I, en Valdeherrera se emplaza Bilbilis II y en el cerro de Bámbola Bilbilis III, con una secuencia ocupacional ininterrumpida desde la Edad del Bronce.

${ }^{8}$ G. LÓPEZ SAMPEDRO, "Para la carta arqueológica del término municipal de Calatayud", Caesaraugusta, 31-32 (1968), pp. 143-157; Ibídem, "Calatayud y la cerámica hispanomusulmana", Pueblo, 7-09-1974; M. A. MARTÍN BUENO, Bilbilis: estudio histórico arqueológico, Zaragoza, 1975. 
con cuatro niveles de entramado de madera cuyos troncos se dispusieron formando capas horizontales paralelas y perpendiculares, técnica que Zozaya consideraba de origen yemení y de época emiral, si bien admite que las continuas intervenciones de consolidación y reforma dificultan un juicio de valor y una data totalmente segura ${ }^{9}$. Sanmiguel propuso la existencia de una cerca amurallada del siglo VIII, protegiendo la primera población, de la que nada ha llegado a nuestros días ${ }^{10}$.

En realidad, el análisis de la presencia musulmana en Calatayud se fundamenta en unas pocas noticias escritas por historiadores musulmanes, en su mayoría tardías e indirectas (ss. XI-XII), algunos epígrafes funerarios, fuentes escritas por los historiadores cristianos medievales (ss. XIII-XVI, aún más indirectas que las fuentes musulmanas) y un conjunto de restos arquitectónicos muy degradados y difíciles de interpretar. Salvo los trabajos de Souto, la mayor parte de los métodos que se han usado para analizar el recinto fortificado de Calatayud contienen importantes contradicciones o se limitan a repetir las teorías consagradas por la historiografía del siglo XIX. Aún a pesar de ello, proponemos el siguiente esquema para el proceso constructivo siguiendo las principales líneas de trabajo actuales, muchas de las cuales, no han logrado superar los acertados planteamientos de Vicente de Lafuente y de otros historiadores decimonónicos ${ }^{11}$.

En la etapa del emirato independiente (756-929), nos consta que Calatayud creció en importancia por ser la cabeza de un distrito militar o kora. Abd al Rahman II, el 14 de diciembre del 842, nombró valí de Zaragoza a Musa ibn Musa, miembro de la familia muladí de los Banu Quasi. El poder de Musa llegó a ser tan notable, que las fuentes cristianas le citan como el tercer rey de España. El emir Muhammad I transformó el castillo de Calatayud en una medina, manteniendo el topónimo Qalat para intentar contrarrestar el poder de los Banu Qasi. Desde entonces la finalidad de Calatayud fue triple: limitar los deseos expansivos de los Banu Qasi, impedir que

9 Una de ellas corresponde a la época de Muhammad I puesto que tiene la misma técnica que se usó en la ampliación del conjunto fortificado. J. ZOZAYA, "La fortificación islámica en la Península Ibérica: Principios de sistematización” L. DE MORA FIGUEROA (ed.), El Castillo Medieval Español. La fortificación española y sus relaciones con la Europea, Madrid, 1998. Se ha discutido mucho por qué razón se encincha de madera el paramento mural de piedra. La respuesta actual más razonable sería para soportar mejor la amplitud térmica de la región ya que el diferencial de calor y frío llega a ser de más menos 20 grados entre el día y la noche, lo que haría reventar el muro si no tuviera cierta flexibilidad de materiales que se dilatan y contraen. Ibidem, "Islamic fortifications in Spain: some aspects", Papers in Iberian Archaeology, British Archaeological Reports, International Series S193, Oxford, 1984, pp. 636-673; Ibídem, "The fortifications of Al-Andalus", Al-Andalus. Las artes islámicas en España, Madrid, 1992, pp. 63-73.

10 A. SANMIGUEL, "La modulación del muro de sillería de la ermita de la Virgen de Consolación de Calatayud, posible sinagoga mayor", IV Encuentro de Estudios Bilbilitanos, vol. I, Zaragoza, 1993, pp. 249253.

11 Hay que destacar las aportaciones de F. ABAD RÍOS, Catálogo monumental de España. Zaragoza, Madrid, 1957; C. GUITART, "El conjunto defensivo de Calatayud", Papeles Bilbilitanos, (1981), pp. 57-75; L. TORRES BALBÁS, "Ciudades hispanomusulmanas de nueva fundación”, Etudes d'orientalisme dédiées a la mémoire de Lévi Provençal, II, París, 1962, pp. 781-803; Ibídem, Ciudades hispanomusulmanas, Madrid, 1981; G. BORRÁS y G. LÓPEZ, Guía de la ciudad monumental de Calatayud, Madrid, 1975, pp. 39-45; J. JIMÉNEZ ESTEBAN, Murallas de España, Madrid, 1993, pp. 102-109; Ibídem, El castillo medieval español y su evolución, Cáceres, 1995, pp. 53-54; A. SANMIGUEL, La huella del Islam en la comarca de Calatayud, Zaragoza, 1995; J. A. SOUTO, El conjunto fortificado islámico de Calatayud, Zaragoza, 2005. 
salieran del valle del Ebro y hostigarles cuando fuera necesario para que reconocieran la autoridad de los Omeyas de Córdoba ${ }^{12}$. No hay una fecha unánimemente aceptada para la transformación de Calatayud en medina. Según Udhri ${ }^{13}$ este hecho aconteció en el 248 de la hégira (862-863), mientras que para Ibn Hayyan fue en el 261 (874-875). Ambos coinciden en que Muhammad I depositó la responsabilidad del gobierno de la medina de Calatayud en Abd al Rahman ibn Abd al-Aziz ibn al-Muhayir al-Tuyubí, la cabeza visible más relevante del clan familiar de los $t u$ yubies, procedentes de Yemen y fieles a los Omeyas ${ }^{14}$. Fueron los tuyubies quienes organizaron el distrito militar construyendo un poderoso castillo en Calatayud, que ejercía su poder sobre un radio de acción de $40 \mathrm{~km}$ a la redonda en el que se fijaron tres husn: Somed, Daroca y Furtish y una serie de atalayas y torres de apoyo ${ }^{15}$. Calatayud tuvo mezquita aljama, muralla, zoco y residencia oficial para el miembro de la familia Tuyubi que ejercía el poder en nombre del emir. La mezquita estaba emplazada en el lugar donde luego se ubicó la iglesia de San Juan de Vallupié, hoy plaza de San Juan el Viejo, ante la puerta principal de la muralla. La plaza nunca ha sido excavada, pero bajo ella están los sustratos arqueológicos de ambos edificios ${ }^{16}$.

12 La fundación de Madrid, obedeció a las mismas razones de ocupación y control del territorio en relación con Toledo. H. GONZÁLEZ ZYMLA, "Los orígenes de Madrid a la luz de la documentación del Archivo de la Real Academia de la Historia", Madrid. Revista de Arte, Geografia e Historia, 5 (2002), pp. 13-44.

13 La teoría de Udhri es actualmente puesta en duda por ser un historiador del siglo XI y, en consecuencia, su data corresponde a una fuente escrita secundaria, aunque no lo es menos Ibn Hayyan puesto que vivió entre los años 897 y 1075.

14 De aquí nace el primer problema de datación del conjunto fortificado, puesto que si son yemeníes los que gobiernan Calatayud en el siglo IX, no es necesario retrotraer al siglo VIII la construcción de los contrafuertes encinchados de madera del castillo de Doña Martina. La consecuencia es que el criterio de datación no es totalmente seguro, de modo que la postura historiográfica tiene partidarios y detractores sin argumentos suficientes para mantener o rechazar la hipótesis. "El emir Muhammad ibn Abd al-Rahman fue el primero en hacer señores clientes a estos Tuyubíes destacados en la Marca Superior, cuando le causaron problemas los Banu Qasi, rebeldes en ella. Preparó contra ellos a esos Tuyubíes, los invistió como señores clientes, los reunió y dispuso como vivienda para ellos la ciudad de Calatayud, en esa marca. La reconstruyó para ellos, la fortificó e introdujo en ella a su caudillo y notable Abd al- Rahman Iben Abd al-Aziz ibn Abdallah ibn al-Muhayir al-Tuyubi, lo nombró oficialmente sobre sus gentes y ordenó a estas consagrarse en torno a él. Reconstruyó para ellos la fortaleza de Daroca y otras, obsequiándoles con dones y asignándoles suplementos por sus campañas [...] Esto tuvo lugar en el año 261/ 16 de octubre del 875”. J. GURÁIEB, Cuadernos de Historia de España, XIII-XIV (1950), p. 175.

15 Según Souto es la distancia aproximada que un hombre puede caminar a pie en un día. J. A. SOUTO, op.cit., 2005, pp. 45-46. El castillo de Somed ha sido localizado y estudiado recientemente: J. MELENDO, "Nuevas aportaciones sobre el complejo defensivo de Somet", V Encuentro de Estudios Bilbilitanos sobre Calatayud y Comarca, Calatayud, 2000, pp. 121-136; Ibidem, Carenas, una historia a la sombra del Cister, Zaragoza, 2005. Furtish no ha sido localizado aún. Del castillo de Daroca, cuya estrecha relación con Calatayud es evidente, existen numerosos estudios: J. JIMÉNEZ ESTEBAN, op.cit., 1993, pp. 110-117; J. L. CORRAL LAFUENTE, Historia de Daroca, Zaragoza, 1983; J BELTRÁN, Historia de Daroca, Zaragoza, 1998. Recientemente di a conocer la localización de una aldea con un recinto fortificado musulmán en el cerro de Piedra Vieja. H. GONZÁLEZ ZYMLA, "Sobre los posibles orígenes del Real Monasterio de Santa María de Piedra: precisiones acerca de su primera ubicación y sentido de su advocación mariana", Anales de Historia del Arte, 13 (2003), pp. 27-82. Para más datos sobre las torres fortificadas existentes en la comarca de Calatayud, entre las cuales deben citarse las torres de Maluenda, Sabiñán, Villafeliche y Ruesca, vid. A. SANMIGUEL, Torres de ascendencia islámica en las comarcas de Calatayud, Zaragoza, 1998, pp. $201-223$.

16 G. BORRÁS, y G. LÓPEZ, op.cit., 1975, pp. 195-196; M. I. ALCÓN, Las ciudades medievales aragonesas, Zaragoza, pp. 1160-1200. 
Del zoco nada se ha conservado. El barranco de la Rua hizo las veces de calle-eje principal de un sistema urbanístico de crecimiento orgánico. La ampliación del sistema de fortificaciones de Calatayud consistió en reforzar el ya existente castillo de Doña Martina, construir un castillo en el punto más alto de la ciudad, el castillo Mayor, también llamado de Ayyub, y completar el sistema defensivo con la construcción de tres castillos llamados del Reloj, de la Torre Mocha y un vacar con torre albarrana. Uniendo los cuatro castillos, se trazaron lienzos de muralla jalonados de torreones de sección cuadrada, que limitaban el recinto urbano dentro del cual estaba el caserío con la población musulmana y judía. Calatayud se convirtió en el conjunto fortificado más importante de la Marca Superior y uno de los más singulares del al-Andalus por estar formado por cuatro castillos, caso único en la Península ${ }^{17}$.

En estas obras se usó la técnica constructiva del tapial que consiste en levantar muros mediante hormas o tableros de madera colocados verticalmente y en paralelo, formando un molde que se rellena de diversos materiales mezclados en distintas proporciones. Las hormas o tableros se mantienen separados a distancias teóricamente regulares (entre $80-100 \mathrm{~cm}$ de altura), usando listones de madera transversales que reciben el nombre de agujas para montarlos y hacer crecer los muros en altura. Una vez aprisionado y seco el fraguado, las hormas se retiran y se procede a la construcción de la siguiente hilada. Souto analizó los materiales de relleno afirmando que desde el punto de vista técnico deben ser relacionados con las tradiciones arquitectónicas yemeníes, y estableció tres técnicas diferentes asociadas a dos campañas constructivas ${ }^{18}$ : El tapial 1 está compuesto por fragmentos de yeso sin tallar, unidos con tierra mezclada con argamasa de yeso compactada; una vez aparejado y fraguado el muro, se enlucía. El tapial 2 está compuesto simplemente de tierra apisonada y dejada secar al aire. El tapial 3 está compuesto de fragmentos de yeso sin tallar, unidos con tierra trabada con paja machacada, con enlucido de argamasa de yeso después de fraguado el muro. Estas tres técnicas arquitectónicas, por su escasa consistencia, se degradan ante los agentes atmosféricos (viento, lluvia, heladas...) y necesitan continuas reparaciones.

17 J. VALLVÉ, La división territorial de la España Musulmana, Madrid, 1986.

18 Usar la medida de las hormas como técnica de datación no es un método fiable, puesto que solo permitiría establecer qué paramentos murales fueron fabricados en la misma campaña y en ocasiones, ni eso, puesto que, como sucede en todos los trabajos artesanos, las hormas no son totalmente homogéneas. Souto diferenciaba dos etapas diferentes en relación con el uso de hormas de 0,60 metros y una segunda etapa con un módulo de 0,50, pero la asociación cronológica de las mismas no es absolutamente irrebatible. J. A. SOUTO, "Notas acerca de dos elementos islámicos en el conjunto fortificado de Calatayud", I Encuentro de Estudios Bilbilitanos, Papeles Bilbilitanos, s. n. (1982), pp. 279-291; Ibídem, op.cit., 2005. La filiación al arte yemení resulta un tópico historiográfico recurrente, puesto que los tuyubies eran naturales de Yemen. La afirmación tradicional de que el castillo de Calatayud se concibe a la manera de las fortificaciones de Yemen pasa por alto las técnicas de construcción locales. El yacimiento romano de Botorrita ha contribuido al conocimiento de los aparejos murales en barro en Aragón desde la época republicana romana. La técnica del encofrado existe y está muy bien documentada en Roma y no es necesario explicar la técnica arquitectónica de los castillos de Calatayud como importada de Yemen. Más bien debe ser consecuencia de la confluencia de los dos factores: la pervivencia de la tradición clásica y el enriquecimiento de la misma con técnicas y formas de trabajo forasteras. S. SAMAR DAMLUJI, The Architecture of Yemen, Londres, 2007; A. BELTRÁN MARTÍNEZ, "Gran edificio de adobe en Contrebia Belaisca (Botorrita): Hipótesis y estado de la cuestión", Boletín del Museo de Zaragoza, 1 (1982), pp. 95-108. 
El edificio más importante del recinto fortificado es el castillo de Ayyub, que recibe el nombre de castillo Mayor o Plaza de Armas, a 534 metros de altitud sobre el nivel del mar. Se sitúa en el punto más elevado de la ciudad, tiene planta irregular de tendencia rectangular y alargada, se levantó sobre roca madre de yeso en la que se talló a pico un foso para aumentar artificialmente la altura y resistencia del recinto y usar la piedra extraída del foso en la fábrica de las torres y los muros. El castillo tiene dos recintos escalonados en altura, más elevado el meridional, limitados por lienzos de muro recto rematados en sus extremos por dos torres que reciben el nombre de qubas, cada una de las cuales está organizada en dos unidades independientes ${ }^{19}$. La unidad habitacional inferior es accesible a través de arcos de medio punto rebajados con dovelas de sillares de yeso dispuestos radialmente y la habitación superior es accesible desde el camino de ronda, al que debía subirse con escaleras de mano, seguramente de madera. El cuerpo inferior de las qubas dispone de zarpa ataludada. Los muros exteriores e interiores estaban enlucidos con argamasa de cal, puede que pintada imitando sillares escuadrados para dar sensación, vistos de lejos, de tener materiales más sólidos. Ambas qubas se ajustan a planta octogonal al exterior y circular al interior, salvo la quba occidental, cuyo cuerpo inferior es de planta cuadrangular cubierto con bóveda de cañón y necesita taludes en pirámide para la transición de la planta cuadrada a la octogonal. Las bóvedas en ambos casos son por aproximación de hiladas de lajas de yeso. El acceso al camino de ronda que hay sobre el tercer piso de cada una de las torres se hacía a través de escaleras intramurales. Ambas torres tienen ventanas orientadas hacia el sur, mirando a la ciudad y al valle del Jalón. En el lienzo de muro situado entre las dos qubas se construyó un cubo semioctogonal al exterior y de planta rectangular al interior. Su habitación, cubierta con bóveda de cañón rebajado, tuvo un forjado de madera intermedio para ganar dos plantas de altura. En el siglo IX el castillo Mayor tenía una única puerta de acceso elevada sobre el foso excavado, junto a la quba occidental, protegida por un camino de ronda, a la que se accedía bien por un puente levadizo sobre foso seco, bien a través de escaleras de mano. Tanto el recinto meridional como el septentrional disponen de aljibes. El aljibe sur tiene planta rectangular y se cubre con bóveda de cañón, mientras que el del recinto norte está derrumbado pero sus restos denuncian ser del mismo tipo y seguramente de la misma capacidad. Según Vicente de la Fuente "por su falta de posibilidad de tener buenos aljibes, nunca sirvieron sino para evitar un golpe de mano, jamás para resistir un largo asedio" ${ }^{20}$.

Al ser el castillo Mayor el punto más alto de Calatayud, nunca perdió su condición de fortaleza, de modo que lo que actualmente se ve es el edificio musulmán construido en el siglo IX, continuamente reparado, reconstruido y ampliado con las mismas técnicas constructivas, mantenidas en la arquitectura popular hasta bien

19 Mantenemos la denominación qubas porque así aparece recogida en la historiografía tradicional: Zozaya, Souto... Sin embargo, en un sentido estricto, son solo torres poligonales y no qubas, puesto que no tienen un uso funerario ni religioso, sino simplemente defensivo. Sanmiguel no las denomina qubas, sino torres, documentando en el conjunto fortificado de Calatayud dos torres rectangulares, dos de planta semioctogonal y cuatro de planta octogonal: A. SANMIGUEL, op.cit., 1998, pp. 201-223.

20 V. DE LA FUENTE, op.cit., 1880. 
entrado el siglo XX, como bien demuestra el muro de los Matuteros, edificado por el Ayuntamiento de Calatayud para evitar el estraperlo, siendo rey Alfonso XIII, hoy tan degradado, que a ojos no habituados a distinguir fases constructivas, pasaría como parte de los recintos fortificados medievales. Entre las transformaciones, a simple vista son evidentes los recrecimientos de muro del siglo XVII, época en que se hicieron refuerzos oblicuos en el lienzo oriental para colocar piezas de artillería. En las guerras del siglo XIX, guerra de la Independencia (1808-1814), guerras Carlistas (1834-1843) y guerras del Sexenio Democrático (1872-1877), se adaptó como fuerte fusilero, se construyó una puerta adintelada y un acceso intramural con escaleras muy estrechas que es el que actualmente se usa para acceder al recinto fortificado. Además, se pusieron troneras, garitas y varias viviendas para el retén allí destinado. Particular importancia tuvieron las reformas hechas en el tiempo que Calatayud fue capital de provincia entre los años 1822 y $1823^{21}$. La comparación de las fotografías de la década de 1900-1930 con la situación actual del conjunto, permite advertir el ritmo de degradación mural acentuado por la debilidad de los materiales constructivos.

Uniendo los diferentes castillos construidos en el siglo IX se edificó una compleja muralla que se adapta a la topografía del terreno y que fue continuamente reparada y ampliada, especialmente con motivo de los desperfectos que sufrió en la guerra de los dos Pedros, entre 1362 y $1365^{22}$. Cuando Pedro I conquistó Calatayud, nombró a Fernán Pérez de Monroig alcaide de Calatayud, con la orden de reparar las murallas y, llegado el caso, arrasarlas e incendiar la ciudad si se veía obligado a retirarse. Desde que en 1365 el ejército castellano abandonó Calatayud, se iniciaron las obras de reparación que continuaban en 1390, siendo rey Juan I.

Las obras de reparación en las murallas, continuamente ampliadas y reparadas durante los siglos XIV, XV y XVI, dificultan la fijación exacta de los tramos construidos en el periodo emiral, califal y taifa. A nuestros días llegan un total de 2.250 $\mathrm{m}$ de muralla, cuya altura oscila entre los 6 y los $15 \mathrm{~m}$ conservándose un total de 26 cubos, algunos muy derruidos. El tramo mejor conservado es el que está situado al norte, con una longitud total de 1.044 metros, 18 cubos y 3 puertas: la de la Longía, muy derruida, la del barranco de la Rúa, aprovechada para apoyar en sus muros la ermita de la Purísima y la puerta situada entre el castillo de Ayyub y el castillo de la Consolación, antes de llegar al barranco de la Rúa. Esta última posee un arco de herradura emiral del siglo IX que tiene dos tercios de alzado respecto del radio, está construido en yeso bien tallado, con el despiece de dovelas enjarjado hasta los riñones y radial al centro de la circunferencia, sin testigos de haber tenido alfiz y con quicialeras al interior. Desde el punto de vista formal puede ser relacionado con la puerta de San Esteban de la mezquita de Córdoba. La erosión del barranco

21 F. NAVARRO AZPEITIA, “Cuando Calatayud fue capital de provincia”, Zaragoza, XXVIII (1968), pp. 11-34.

22 A. GUTIÉRREZ DE VELASCO, "Las fortalezas aragonesas ante la gran ofensiva castellana de la Guerra de los dos Pedros", Revista de Historia Jerónimo Zurita, 12-13 (1961), pp. 7-39; Ibídem, "La contraofensiva aragonesa en la Guerra de los dos Pedros" Revista de Historia Jerónimo Zurita, 14-15 (1962), pp. 7-30. 
impide ver que era la puerta principal del sector norte de la muralla. En tiempos de Muhammad I Calatayud tenía dos puertas principales, ninguna de las cuales ha llegado a nuestros días: la puerta de Valencia, junto al castillo de Doña Martina y al lado de la mezquita aljama, y la puerta de Soria. En el extremo occidental del muro norte subsisten 72 metros de muralla, que en opinión de Guitart eran un revellín ${ }^{23}$.

El conjunto fortificado se completaba con el castillo del Reloj, que está muy deteriorado y apenas puede ser enjuiciado, dada la reutilización de materiales. A unos metros del tramo norte de la muralla, al oeste del castillo Mayor, se yergue una esbelta torre de planta cuadrada que debe ser considerada una torre al-barrani, es decir, exterior. Si aceptamos, como hace Souto, que fue edificada en tiempos de Muhammad I, estaríamos ante el ejemplo más antiguo de albarrana conocido para la arquitectura militar andalusí ${ }^{24}$. La torre tiene dos estancias abovedadas en medio cañón y escalera intramural en recodo. Sobre uno de los cerros de poniente, se construyó la torre Mocha, que aunque se le ha citado en numerosas publicaciones como castillo de la Torre Mocha, no es verdaderamente un castillo sino un recinto cerrado solidario con los castillos de Ayyub y de Doña Martina, conectado con ambos con la ayuda de la muralla, que se usaba como albacara ${ }^{25}$. En la parte central del castillo de la Torre Mocha se sitúa una torre de planta octogonal con bóvedas por aproximación de hiladas, en cuyo cuerpo inferior hay un aljibe y cuya toponimia servía para dar nombre a la totalidad del castillo al vacar. Hay quienes afirman que la torre fue una coracha (de ahí la necesidad de un aljibe propio) asumida como parte de las murallas al ampliarlas. En tal caso, la torre habría perdido su función militar y quedaría integrada en el vacar sin una utilidad concreta más allá de la derivada de vigilar el ganado allí guardado.

La historia de Calatayud entre los siglos IX y XI y la evolución del proceso constructivo de sus castillos y recintos amurallados, quedó condicionado por las complejas relaciones de los Banu Qasi, los Omeyas y los Tuyubies, que continuamente firmaban y rompían alianzas. En el siglo X el clan de los Tuyubíes logró adueñarse de Zaragoza y controlar con cuatro ramas familiares diferentes, la totalidad de la Marca Superior, que gobernaban desde Tudela, Lérida, Calatayud y Zaragoza ${ }^{26}$. En-

23 C. GUITART, "El conjunto defensivo de Calatayud", Boletín de la Sociedad Española de Amigos de los Castillos, 7-24, 1959, pp. 5-12.

24 J. A. SOUTO, op. cit., 2005.

25 No se ha hecho un estudio riguroso del poblamiento musulmán en los valles del Jalón y el Jiloca. Las crónicas hablan de ciudades, castillos y recintos fortificados, pero casi no hablan de aldeas ni poblaciones sedentarias menores. Esta ausencia de datos, hace pensar que la principal actividad económica era la ganadería, que permitiría un aprovechamiento de pastos en los páramos pobres y que el modo de vivir de sus pobladores sería nómada o semi-nómada. Al ser un territorio fronterizo y expuesto a continuas luchas de poder, la ganadería sería la actividad económica más rentable y quizá la única sin riesgo, puesto que en caso de invasión o ataque, los recintos fortificados que formaban las cabezas de cada distrito militar, disponían de espacio suficiente dentro de sus murallas, para guardar los ganados con cierta comodidad. Cuando tales recintos son separados de las áreas habitadas reciben el nombre de albacara. El tamaño del al-vacar de Calatayud y su torre de vigilancia, acaso destinada a vigilar por las noches el ganado y evitar su robo, es prueba inequívoca de que la actividad económica más importante de la ciudad musulmana fue la ganadería ovina, como lo ha sido hasta bien entrado el siglo XX.

26 A, G. CHEJNE, op.cit., 1980. 
tre el 862 y el 934 los Tuyubies bilbilitanos fueron fieles a los Omeyas y hostigaron a los Banu Qasi. La sucesión en el poder se hizo de padres a hijos sin que se documenten problemas dinásticos ni de legitimidad. El primogénito gobernaba desde Calatayud y los hermanos, en caso de haberlos, gobernaban los castillos del distrito subordinados. En el 277 de la hégira (890-891) el emir Abdallah confirmó como sahib de Calatayud a al-Mundhir ibn Abd al-Rahman ibn Abd al-Aziz al-Tuyibí, que murió en el 312 de la Hégira (924-925).

El califato Omeya de Córdoba (929-1031) marcó uno de los momentos de clímax político, cultural y militar andalusí. Comenzó en el año 929 con la autoproclamación de Abd al-Rahman III como califa de Córdoba y, en paralelo con una notable conflictividad en la Marca Superior en la que Calatayud hubo de jugar un papel histórico decisivo ${ }^{27}$. El 21 de julio del 930 Abd al-Rahman III confirmó en Calatayud a Mutarrif ibn al-Mundhir y en Daroca a su hermano Yunus Ibn Abd alAziz al-Tuyibí. En el 934 el sahib de Zaragoza, Muhammad ibn Hashim al-Tuyibí, primo de Mutarrif y de Yunus, se rebeló contra la autoridad de los Omeyas de Córdoba e invocó a los vínculos de consanguineidad para que también se rebelaran los bilbilitanos. Al principio Mutarrif y Yunus se mantuvieron fieles a Abd al-Rahman III, pero en el 935 Yunus se desmarcó y se alió con Hashim. Calatayud se mantuvo fiel a Abd al-Rahman III que envió a parte de su ejército en el mes de mayo para someter Zaragoza y Daroca. Yunus, temeroso, huyó de Daroca con sus hijos y se refugió en Zaragoza. Al abandonar los husn, Abd al- Rahman III pudo controlar nuevamente los pasos naturales que conducían a la capital del Ebro: el del oeste en Calatayud, a través de su aliado, Mutarrif, y el del sur, a través de Daroca, abandonado por Yunus y ocupado pacíficamente. Abd al-Rahman III fundó el campamento de Al-Yazhira para, desde él, hostigar Zaragoza. Cuando parecía que Hashim se iba a rendir, recibió el auxilio de Ramiro II y de la intrigante reina Toda. En abril del 936, Al-Nasir envió a Zaragoza al caíd Abd al-Hamid ibn Basil con tropas y más tarde, con refuerzos, al visir caíd Sa' id ibn al-Mundhir al-Qurashi, que llevaba la orden de destituir al responsable del asedio de Zaragoza, Ahmad ibn Ishaq alQurashi, y dirigir personalmente las operaciones militares. Según Udri, Ahmad, ávido de venganza "hizo alto en Calatayud para ver a Mutarrif y le metió miedo con historias que había inventado. Mutarrif se declaró en rebeldía y buscó la alianza con Muhammad ibn Hashim" 28 . Ante esta nueva situación, Yunus regresó a Daroca en el otoño del 936. Fue así como los rebeldes a Abd al-Rahman III controlaron nuevamente los valles del Jalón y el Jiloca, cortando totalmente los suministros al campamento de Al-Yazhira. El 28 de mayo del 937 Abd al-Rahman III diseñó una campaña contra la Marca Superior. En junio el ejército califal llegó a Gallocanta. Mutarrif se había aliado con alaveses y castellanos, que acudieron a Calatayud para ayudarle. Yunus, al saber de la llegada del califa, volvió a evacuar Daroca e intentó hacer frente común con su hermano "dejando treinta fortalezas y alcazabas de sus

27 H. GONZÁLEZ ZYMLA, Año 929: Las claves del Califato de Córdoba, Madrid, 2010.

28 J. A. SOUTO, op. cit, 2005. 
distritos, que pasaron pacíficamente" a ser controladas por el califa ${ }^{29}$. Calatayud fue tomada por la fuerza, tras un duro asedio. Yunus y Mutarrif fueron ejecutados. Hakam Ibn al-Mundhir se encastilló en la alcazaba y obtuvo el perdón del califa al capitular el 31 de julio del 937.

Abd al-Rahman III puso al frente de Calatayud a un alto funcionario cordobés, Suleyman ibn Ahmad ibn Yudí. Hashim perdió todos sus apoyos. El castillo de Calatayud, que había sido parte del sistema defensivo de Zaragoza cuando era gobernado por Mutarrif, pasó a ser la retaguardia del sistema ofensivo califal. Zaragoza cayó el 21 de noviembre del 937. A su regreso a Córdoba, al pasar por Calatayud, Abd al-Rahman III nombró vali de su castillo a Muhammad ibn Asbag. El 25 de enero del 939 fue nombrado Ubaydallah ibn Fihr. El 12 de julio del 940 fue confirmado Hakam ibn al-Mundhir al-Tuyubí en recompensa por su fidelidad. Tras su muerte, el 24 de febrero del 950 le sucedió su hijo Al 'Asi ibn Hakam, que gobernó hasta el 350 de la Hégira (961-962). Entre los años 971 y 975 los Omeyas mantuvieron a las cuatro ramas de la familia de los Tuyubies alejados de sus tierras: Tudela, Zaragoza, Calatayud y Lérida, sin que nos conste la razón, aunque podría pensarse en el temor a una nueva rebelión ${ }^{30}$. Entre los meses de mayo y julio del 981 Almanzor capitaneó su tercera campaña, en el transcurso de la cual, estando en Calatayud, nombró valí de la ciudad a Abd al-Aziz ibn Hakam ibn al-Mundhir, que se había unido a Almanzor en contra de su hermano. En el 997 los navarros atacaron Calatayud. En el asedio del castillo perdió la vida el hermano de Hakam ibn Abd al-Aziz ibn Hakam ${ }^{31}$. En paralelo a esta compleja trama de conspiraciones familiares entre hermanos para hacerse con el control de los valles del Jalón y el Jiloca, los castillos de Calatayud fueron asediados varias veces, sufrieron deterioros, reparaciones, recrecimientos murales... Tantos y tan seguidos cambios dieron a los paramentos murales una fisonomía compleja que hoy los convierte en un campo de estudio complejo, de data poco menos que imposible, en el que quedan muchas cosas por decir.

En el periodo taifa, tanto en la etapa tuyubi (1013-1040) como en la etapa hudi (1040-1110), Calatayud dependió de Zaragoza y de sus reyes, de modo que ambas ciudades corrieron un mismo destino político, paralelo a las vicisitudes de estas familias, a sus intrigas y a los laberintos políticos de alianzas, regicidios y conspiraciones. El primer rey de la taifa de Zaragoza en la dinastía Banu Hud, Sulayman al-Musta'in, controló el territorio repartiendo entre sus hijos, convertidos en gobernadores, los castillos: a Ahmad le confió su sucesión en Zaragoza ${ }^{32}$, a Muhammad le concedió el control de Calatayud, a Lubb Huesca, a Mundhir Tudela y a Yusuf

29 E. LÉVI-PROVENÇAL, La Péninsule Ibérique au Moyen-Age d'après le Kitab Ar-Rawd Al-Mi'tar fi Habar Al-Aktar d'Ibn 'Abd al-Mun'im al-Himyari, Leiden, 1938.

30 M. J. VIGUERA MOLINS, El Islam en Aragón, Zaragoza, 1995.

31 M. AVILÉS FERNÁNDEZ et alii, La España musulmana. Califato y reinos de Taifas, Madrid, 1973; J. A. CONDE, Historia de la dominación de los árabes en España, sacada de varios manuscritos y memorias arábigas, Madrid, 1820-1821; IBN IDARI AL-MARRAKUSI, Historia de los Reyes de Al-Ándalus y de Marruecos, E. LÉVI-PROVENÇAL (trad.), 1951; J. VALLVÉ, Abderramán III. Califa de España y Occidente (912-961), Barcelona, 2003.

32 Es el que ha pasado a la historia como Abu Ya' far al-Muqtadir, el constructor del palacio de la Aljafería. 
Lérida. Muhammad tomó el sobrenombre de Adud ad Dawla y gobernó en exclusiva Calatayud entre los años 1046 y 1051, llegando a acuñar moneda, lo que equivale a poder afirmar que en aquellos años Calatayud fue un reino independiente o casi autónomo dentro de la taifa ${ }^{33}$. Rodrigo Díaz de Vivar, El Cid (1043-1099), después de ser desterrado por Alfonso VI de Castilla, entró en el territorio de Calatayud, se asentó en Torrecid y atacó Ateca, Alcocer y Terrer con el único fin de saquear y obtener botín. En el siglo XI se tiene noticia de varios hombres de ciencia bilbilitanos: Abd Allah al- Batruri al-Qal'i (padre e hijo) y Yahya ibn Muhammad ibn Hassan ${ }^{34}$.

En el año 1086 cambió radicalmente el panorama político de las taifas al producirse la entrada de los almorávides en al-Andalus. El 31 de mayo de 1110 Zaragoza fue ocupada por el general Ibn al Hayy, lo que marcó el fin de la taifa. Los almorávides atacaron, entre otros castillos, el de Calatayud. En 1115 sucedió en el poder el emir Ibn Tilwit, que vivió en Zaragoza hasta 1117. A su muerte la capital del Ebro no recibió un gobernador almorávide y quedó a merced de Alfonso I el Batallador, que entró en la Aljafería el 11 de junio de 1118 y en la ciudad el 18 de diciembre tras un tedioso asedio. El 17 de junio de 1120, Alfonso I derrotó a Ibrahim Yusuf, gobernador de Sevilla y hermano del emir almorávide, en la batalla de Cutanda y quedó fijada la frontera cristiana. Para vencer en Cutanda hubo de levantar el asedio de Calatayud, ciudad en la que entró el 24 de junio de 1120, cuando sus habitantes comprendieron que los almorávides habían sido derrotados y que no recibirían su apoyo. En 1122 capituló Daroca y en 1128 Molina de Aragón. El dominio cristiano de la taifa de Zaragoza supuso un nuevo capítulo artístico para el castillo de Calatayud en el que todavía quedan muchas cosas por aclarar ${ }^{35}$.

A manera de conclusión podemos afirmar que el estudio de los castillos musulmanes, murallas, puertas y urbanismo de Calatayud, constituye un interesante campo de análisis por ser uno de los recintos fortificados más antiguos y complejos del arte hispanomusulmán, fundado quizá por el III valí, Ayyub ibn Habib, que gobernó al- Andalus en el 716 y dio su nombre a la ciudad. Combinando las fuentes escritas, los restos materiales, las prospecciones arqueológicas y los estudios formales comparativos, varios historiadores han formulado diferentes hipótesis acerca de su proceso constructivo. Existe un primer recinto, de época emiral dependiente de Damasco, es decir, del siglo VIII, ubicado en lo que actualmente llamamos castillo de Doña Martina, que usaba paramentos murales de sillería reutilizando materiales procedentes de Bilbilis. El emir Muhammad I en el siglo IX (hacia 862) transformó el castillo en una medina, mantuvo el nombre, depositó su gobierno en manos del clan yemení de los Tuyubies (su primer alcaide fue Abd al-Rahman ben Abd al-Aziz al-Tuyibi), creó una mezquita aljama, un zoco y construyó cuatro castillos -unidos al ya existente con imponentes murallas en las que aún se conserva una de las puertas en arco de herradura- llamados del Reloj o Real, de la Torre Mocha, de la Longía y de la Peña, obras todas ellas construidas en tapial con sillarejo de yeso.

33 A. CANTO, T. HAFIZZ y F. MARTÍN, Monedas andalusies, Madrid, 2000.

34 J. A. SOUTO, op. cit., 2005.

35 A. BENAVIDES, Las repúblicas musulmanas en España, Madrid, 1873; P. IRADIEL, S. MORETA, y E. SARASA, Historia Medieval de la España Cristiana, Madrid, 1989, pp. 284-285. 
En el siglo X, durante el califato de Abd al- Rahman III, el castillo de Calatayud, continuamente asaltado y reparado en sus daños, jugó un papel sobresaliente en los conflictos de la Marca Superior, papel histórico que no decreció en la época taifa, cuando la ciudad alcanzó tal grado de independencia, que llegó a tener ceca de moneda propia. Tras la conquista cristiana a los almorávides en 1120, los recintos fortificados conocieron continuas reparaciones y reedificaciones, especialmente importantes son las del siglo XIV, hechas durante y después de la guerra de los dos Pedros. Incluso hay obras de reparación y reforma en el siglo XVII (castillo adaptado a su uso artillero), XIX (fuerte fusilero) y hasta en el siglo XX (construcción del muro de los Matuteros). Tal complejidad, arquitectónica, técnica, geoestratégica y artística lo convierten en uno de los castillos más importantes de la Edad Media hispana, cuyo estudio es aún hoy objeto de vivos debates.

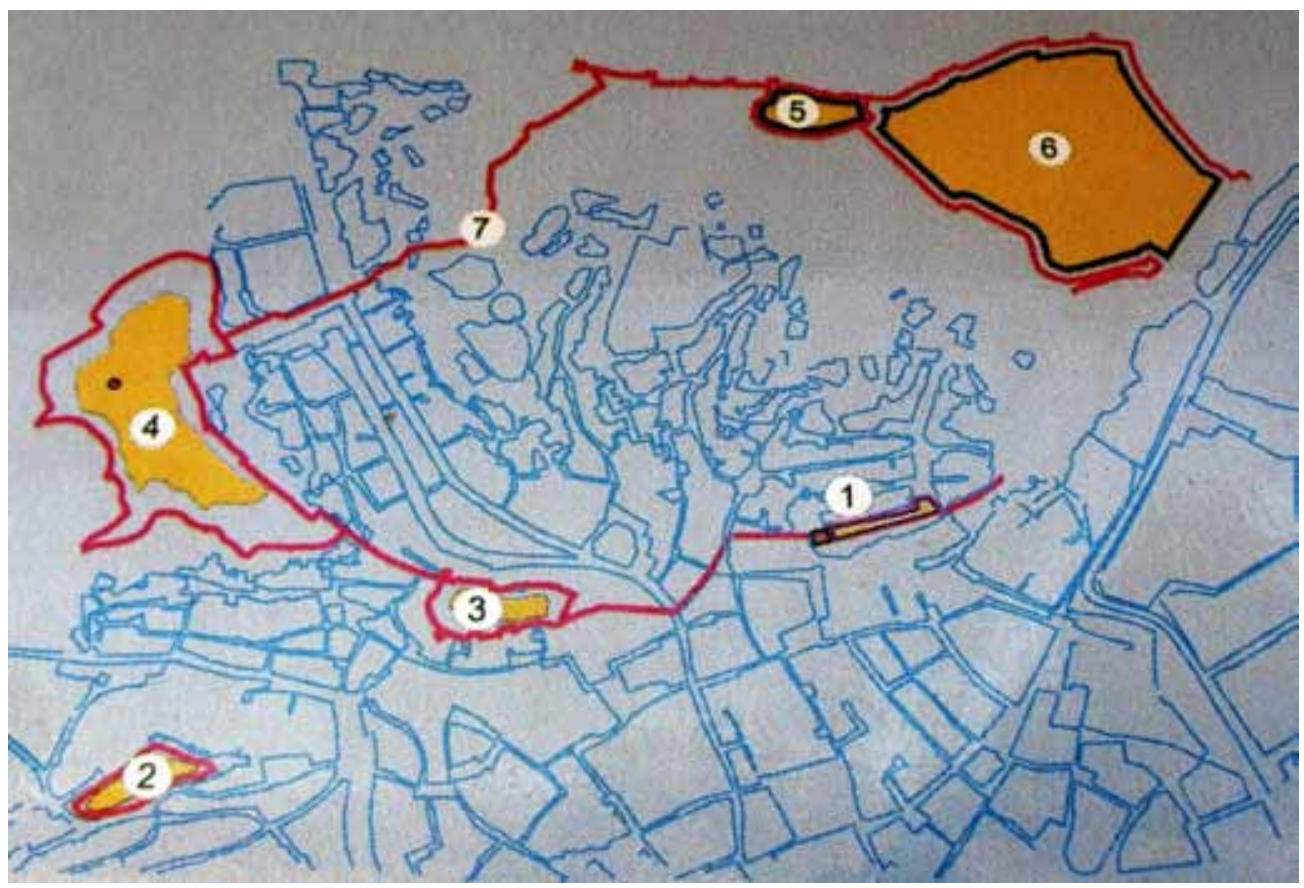

Fig. 1. Planimetría de los castillos de Calatayud: 1: Castillo Real o del Reloj Tonto. 2:

Castillo de la Peña. 3: Castillo de Doña Martina. 4: Castillo de la Torre Mocha. 5: Castillo Mayor o de Ayyub. 6: La Longía. 7: Puerta Emiral. 


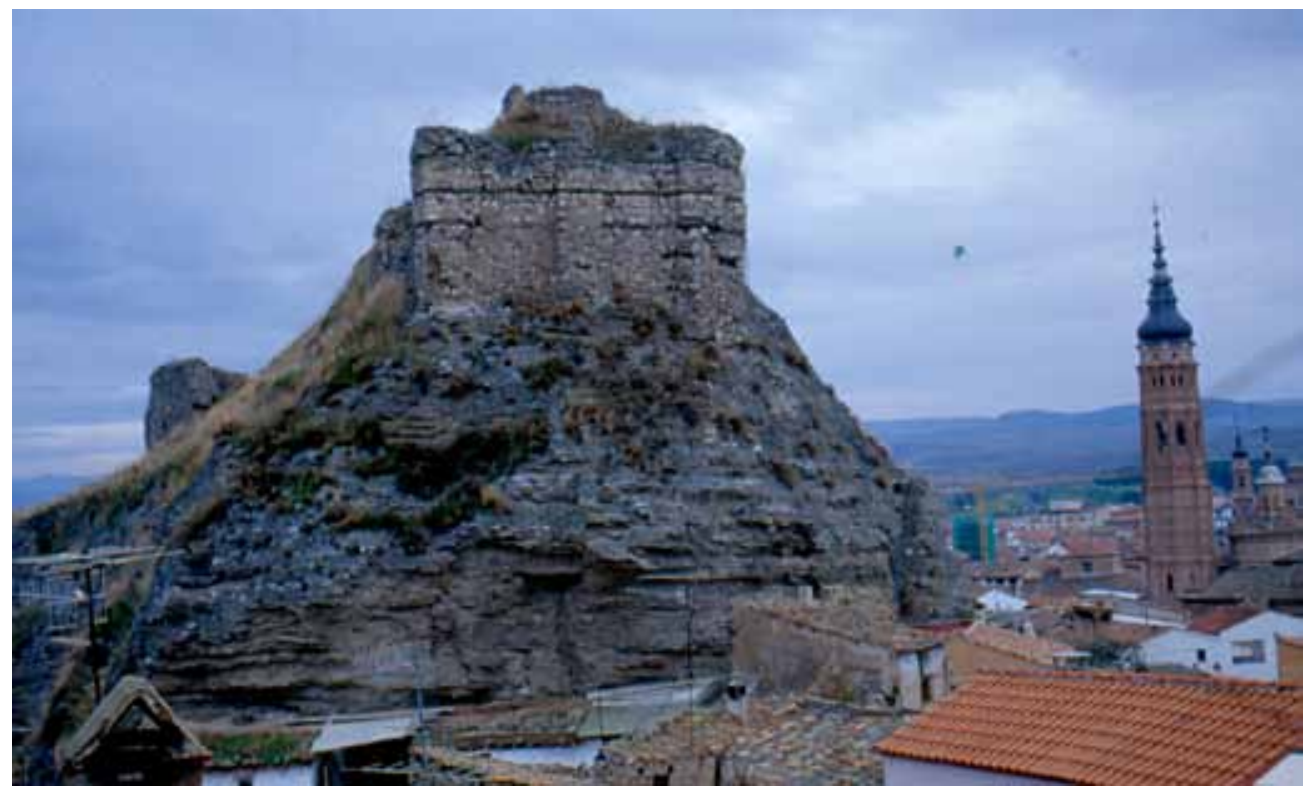

Fig. 2. Paramento mural occidental del Castillo de Doña Martina o de Don Álvaro, s. VIII.

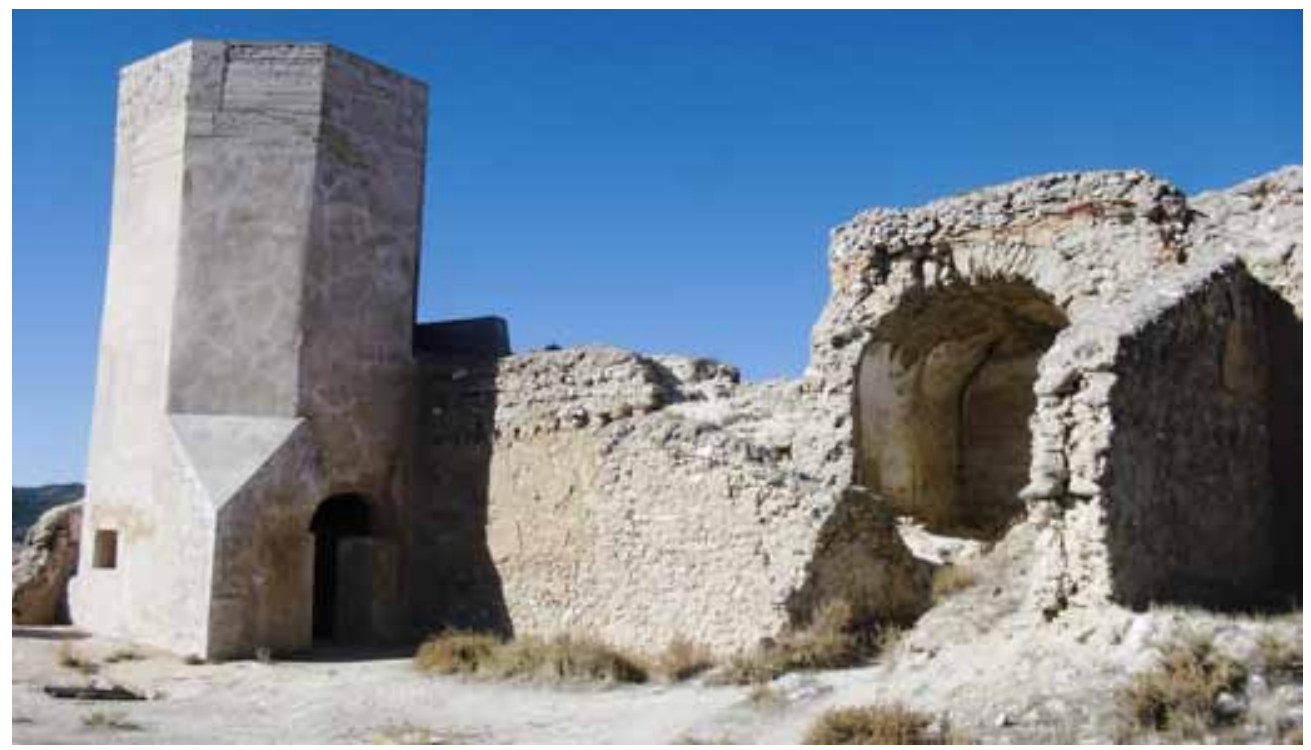

Fig. 3. Torre de sección octogonal y plaza de armas con aljibe del Castillo Mayor de Calatayud, s. IX. 


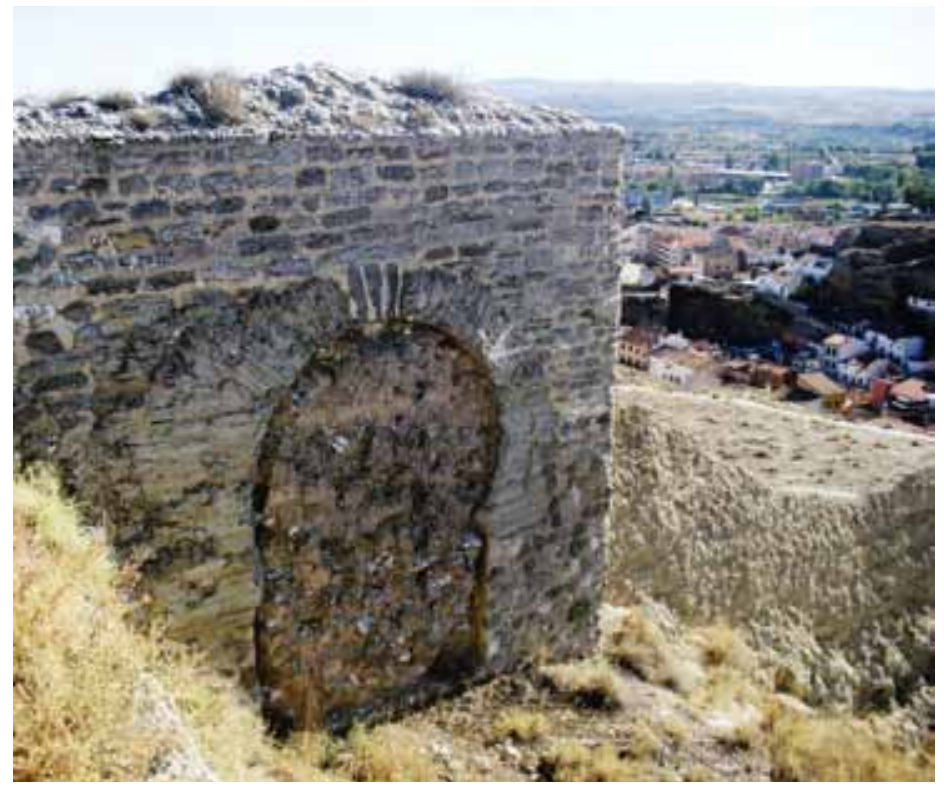

Fig. 4. Puerta en arco de herradura emiral, abierta en el sector norte de la muralla de Calatayud, s. IX.

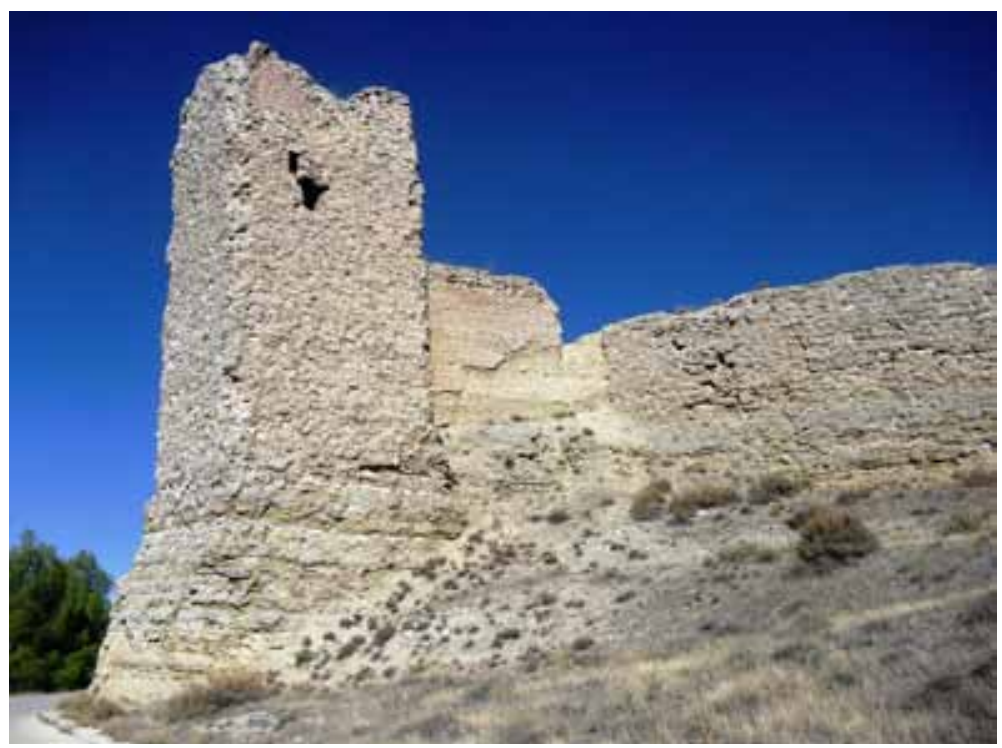

Fig. 5. Torre albarrana y foso excavado en el sector occidental del tramo norte de la muralla de Calatayud, s. IX. 